\title{
Configuración de mecanismos de autorrepresentación: el caso del rap en Cartagena
}

\author{
Osiris Chajín Mendoza ${ }^{1}$ \\ Universidad de Cartagena
}

\section{Resumen}

Esta exploración intenta describir la referencialidad cotidiana de los sujetos juveniles populares urbanos desde el rap como práctica lírica dentro del movimiento hip-hop en la ciudad de Cartagena. La primera parte del ensayo contiene una descripción del origen y desarrollo del hiphop en la cual se detalla el origen y desarrollo del mismo en Cartagena hasta el momento de la presentación de este informe. La segunda presenta la exploración de algunos discursos que circulan en las letras de las canciones de rap cartagenero. Finalmente,

\section{Abstract}

This exploration tries to describe the daily referentiality of the urban popular juvenile individuals from the rap as a lyrical practice inside the hip-hop movement in the city of Cartagena. The first part of the essay contains a description of the origin and development of the hip-hop in which is detailed the origin and development of itself in Cartagena up to the presentation of this report. The second part presents the exploration of some speeches that circulate in the lyrics of rap from Cartagena. Finally, possible linesenses implied in the investiga-

\footnotetext{
${ }^{1}$ Profesional en Lingüística y Literatura de la Facultad de Ciencias Sociales de la Universidad de Cartagena. Aspirante a Magíster en Estudios de la Cultura con mención en Comunicación de la Universidad Andina Simón Bolívar. Gestora y coordinadora del grupo de investigación "Sensorium" y docente de la Universidad de Cartagena y de la Universidad Jorge Tadeo Lozano. Este documento es una versión del informe de investigación que presentó como tesis para obtener el título de Profesional en Lingüística y Literatura en agosto 2004. El ejercicio de Investigación del que trata fue realizado en el grupo de estudios "Urdimbre" de la Universidad de Cartagena entre 2000 y 2002. Las informaciones a estudiar fueron recolectadas en un trabajo de campo realizado en distintos lugares de la ciudad de Cartagena en el año 2001, al que se suma la observación sostenida del trabajo de unos diez grupos de artistas, que conformaban La HeroiK, una organización informal de hiphop, entre agosto de 2001 y febrero de 2002.
} 
a manera de cierre, se indican posibles líneas-sentidos implicadas en la de investigación del fenómeno hip-hop. tion of the phenomenon hip-hop are indicated.

Palabras clave: rap, hip-hop, Keywords: rap, hip-hop, young jóvenes, ciudad, identidades. people, city, identities.

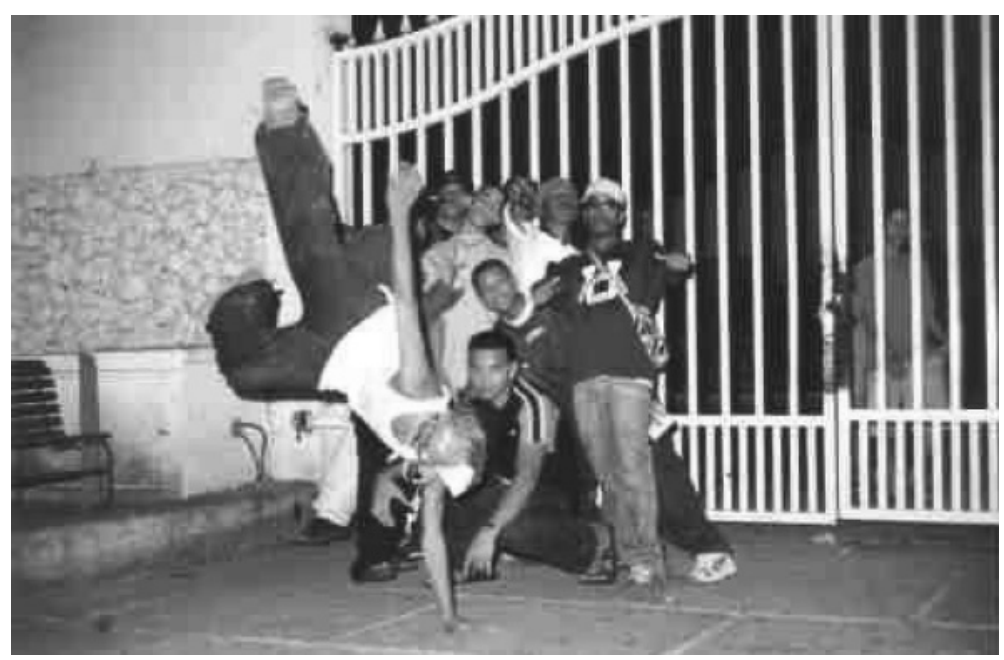

Breaker de La Heroika Movimiento Hip-Hop (2001).

\section{Introducción}

Esta exploración intenta describir la referencialidad cotidiana de los sujetos juveniles populares urbanos, desde el rap como práctica lírica, dentro del movimiento hip-hop de la ciudad. En primer lugar presentamos una descripción del origen y desarrollo del hip-hop, detallando además el origen y desarrollo del mismo en Cartagena hasta el momento de la presentación de este informe. En segundo lugar, se incluye la indagación de algunos discursos que circulan en las letras de las canciones de rap cartagenero. Finalmente, a manera de cierre, se indican posibles líneas de discusión en la investigación del fenómeno hip-hop.

En este contexto, pensamos que intentar comprender la relación juventud-cultura a través de mecanismos de autorrepresentación de los jóvenes, entiéndase sujetos juveniles populares urbanos, requiere al menos dos pasos: a) comprender la cultura como el espacio de la puesta en escena de las costumbres, los discursos y representaciones que los miembros de una comunidad realizan, es decir, "el ámbito de producción, circulación y consumo de significaciones" (García 
Canclini, citado por Pérez Islas, 1998: 46), y b) escoger y analizar una práctica cultural específica, pensada como el espacio de sentidos donde convergen las socialidades que dan cuerpo a una comunidad.

Los mecanismos de autorrepresentación de los sujetos que nos ocupan no se presentan sólo en los discursos que circulan con sus líricas, sino también en discursividades no lingüísticas, como los arreglos musicales, vestuario, rituales de puesta en escena, no sólo en el tinglado, sino también en la cotidianidad. En lo que respecta a los andamiajes sonoros, escuchando rap cartagenero encontramos que las pistas o arreglos son muy sencillos; sin embargo, resulta interesante la mezcla de ritmos y de sonidos de distintos orígenes.

\section{“Este es mi viaje ${ }^{2}$ / y tú tienes que entender/ que las cosas son/ como tienen que ser". Orígenes de una mediación}

Son muy diversos los elementos que convergen para el surgimiento de la práctica cultural que nos ocupa. Si hacemos caso de los testimonios de los jóvenes y de los artículos de algunos historiadores del hip-hop ${ }^{3}$, se debe considerar a la figura del griot ${ }^{4}$-una suerte de "trovador" africano, "palabrero", poeta, cronista, errante, místico y alborotador público- como el antecedente que provee al rap de una raíz afro, en tanto el griot es la conexión con la riqueza cultural de África.

Ahora, siguiendo con el hip-hop: un conjunto de elementos sociales y musicales, conjugados en un contexto socioeconómico particular, los guetos neoyorquinos y posteriormente de otras ciudades norteamericanas vinculado con un grupo social, con unas coordenadas de existencia ya bastante problemáticas y finalmente convertido en fenómeno del mercado. Al intentar delinear el origen y carácter del hip-hop bosquejamos una definición del complejo hecho cultural que sostiene la figura de un negro cartagenero rapeando

\footnotetext{
${ }^{2}$ Término de amplio uso por parte de los jóvenes que hace referencia a una postura, una forma de pensamiento que se comparte, sinónimo de la "vuelta". Este es un verso del grupo Fusión Latina. Versos de la canción del grupo La Fusión Latina.

3 Todos los datos sobre la historia del hip-hop que aparece a continuación, a menos que se indique lo contrario, fueron recogidos en talleres y reuniones de La Heroik, Movimiento Hip-Hop, y en charlas individuales con varios miembros del movimiento.

${ }^{4}$ Este personaje del folclore africano es heredado, según Ángel Perea, en el estilo de los ministros religiosos y los discursos de los protagonistas negros de la historia norteamericana Esto, sumado al scat, fraseo rítmico y vocal que imita el sonido de los instrumentos musicales, a la sensualidad del soul y a los toasters o "disc-jockeys callejeros de Jamaica”, con sus "sound systems" (Perea, 1996: 4).
} 
en un bus de servicio público. Este hermano mediático de AfriKA Bambaataa, Public Enemy, Ice T, Dr. Dre, Orishas y muchos otros, es el resultado de algo que se gestó en el decenio del setenta, en el seno de los guetos negros de Nueva York, según coinciden varios autores, aunque son innegables los aportes latinos y caribeños. Es compartido también que es en los años ochenta cuando el fenómeno se hace popular (Keller, citado por Marín y Muñoz, 2002: 142-143).

Una breve reseña de la historia discográfica del hip-hop debe decir que a finales de dicho decenio apareció el disco Rappers Delight, de Sugar Hill Gang. Es allí donde se escuchan por primera vez las palabras hip-hop. A este disco se sumó un trabajo titulado The Break. A partir de entonces, de los guetos llegó a la industria del disco un género nuevo: "Una base de ritmos cruzados y batallantes, estrujada por un sinnúmero de efectos sonoros alternos y sinuosos" (Perea, 1996:1). Para referirse al sonido actual, el mismo autor define el rap como una forma de canción hablada que utiliza el lenguaje para crear ritmos y rimas que se imponen sobre una banda sonora compuesta por fragmentos de música recogidos de otras grabaciones, además de efectos de sonido que se organizan para crear una obra musical nueva y original, lo cual requiere una gran destreza en el manejo de técnicas de grabación (3).

El rap es una práctica cultural en la que el protagonista es el mcing o "rapper". Esta figura pertenece a una manifestación cultural más amplia, el hip-hop, constituida por el graffitero, el breaker (también conocidos como b-boys y b-girls), el djing (disc-jockey) y el mcing o maestro de ceremonia. Ocurrió que la figura del djing contribuyó a congregar a la comunidad. Son legendarias las figuras de DJ Kool Herc, el creador de los break-beat, "corte rítmico que constituye la base del hip-hop, el jungles y el big beat" (Muñoz, 2000: 17) o en términos laicos, pinchar simultáneamente dos copias del mismo disco, y de AfriKA Bambaataa, el que convirtió los enfrentamientos violentos por territorio en combates de danza callejera, y Grandmaster Flash, el perfeccionador del scratching.

Durante mucho tiempo los djings animaron al público. Pero dice Grandmaster Flash que la gente se congregaba a escuchar y lo que se quería era que bailara, es cuando el djing pide ayuda. Al comienzo los mcings eran sólo animadores del show del djing, pero poco a poco su discurso se va haciendo más elaborado hasta convertirse el mcing en la figura central, siendo este cuarto y último elemento el de mayor proliferación en Cartagena a la fecha. 


\section{Bosquejo de algunos rasgos distintivos de la "vuelta" a nivel local}

Algunos espacios públicos de Cartagena fungen de escenarios donde los raperos presentan lo que para ellos es más que un espectáculo. Duetos, tríos y pocas veces grupos más numerosos nacen y mueren día a día, creados por alianzas fundadas en varios factores: afinidades de estilo, barriada, favores, buenas voces, tenencia de pistas, grabadoras, líricas, "estar en el mismo viaje", etc.

Haciendo una síntesis de varios testimonios de raperos podemos resumir el desarrollo del rap en Cartagena de la siguiente manera: corría el decenio de los ochenta cuando por influencia de las películas y la música norteamericana se empiezan a crear grupos de break por toda la ciudad, "todos bailaban". Los jóvenes intentaban alcanzar la destreza de las figuras de las películas y los videos. Coinciden varios testimonios en que los "piques" más nombrados se organizaban en el parque de Los Leones, por el Pie de la Popa, y en Getsemaní, por la iglesia de la Trinidad. Los perdedores no siempre aceptaban la derrota y aparecían los cuchillos, las cadenas y las piedras, "la otra parte de la película", como lo recuerda El Maestro, integrante de Griot.

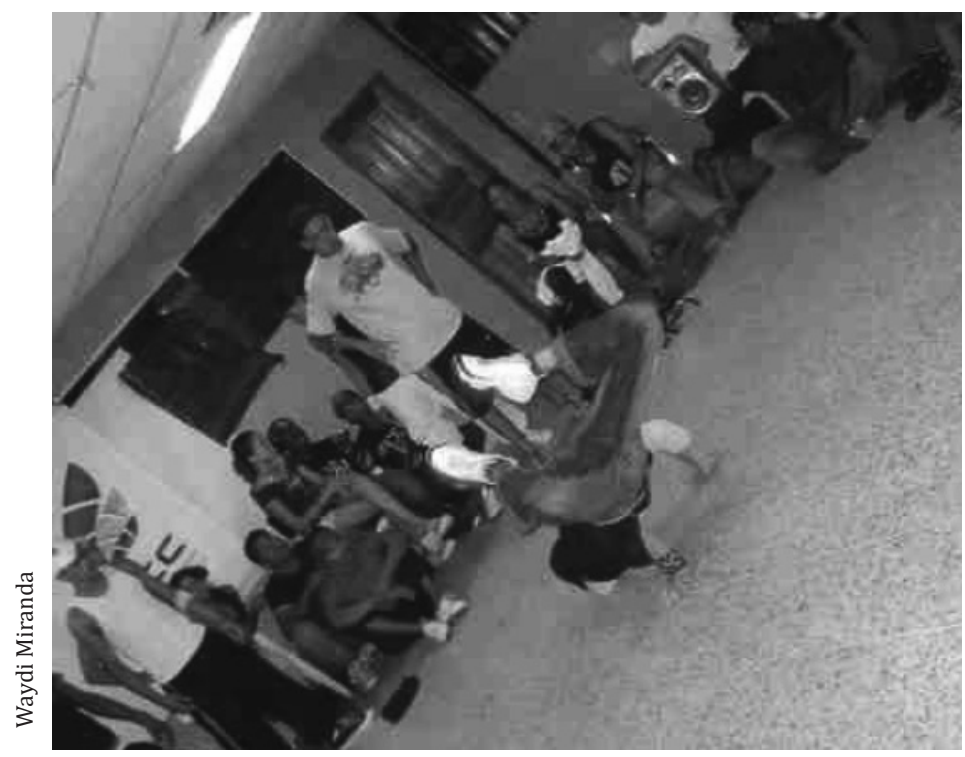

Presentacion de los Reyes del Piso. Biblioteca Jorge Artel (2007).

Por la misma época entra a Cartagena la llamada champeta africana, acompañada de la terapia, una música y un baile con visibles raíces y ramas negras, lo cual le dio mucho auge, "noqueando" al break. De 
este último la terapia toma algunos elementos de puesta en escena. Cuenta un seguidor del grupo O. P. P. que "los champe empezaron a meterse en las presentaciones y también querían imitar la ropa [...]". Simultáneamente en algunos sectores entran con mucha fuerza por el auge de las discotecas, el pop, el house y el disco.

Pensar que ese entran a la ciudad se refiere a la visibilidad que estaba tomando el fenómeno champeta, el cual dejaba de ser sólo asunto de "picoteros" con gustos exóticos y se metía ya en los medios de difusión locales y en los espacios hasta ese momento dominados por el break. Lo anterior puede ayudar a esclarecer los testimonios sobre una llegada posterior de aquella música a Cartagena con respecto al hip-hop.

Tiempo después entra con mucha fuerza vía Panamá la música ragga, mezcla de reggae ${ }^{5}$ y rap. Ya no se hacen "piques" y el hip-hop entra en una suerte de letargo hasta que empiezan a escucharse grupos que no logran mayor trascendencia, pero que introducen la técnica de imitar los instrumentos musicales renovándose así con este rap ya en español "la vuelta" del hip-hop, pero ya no con el break, sino con el rap. Es cuando reaparecen grupos como P. S. B., Dexter's Boys, Black and White, Charly's Boys, los cuales tomaron mucha fuerza en el ámbito juvenil.

Estamos ya en los noventa cuando una emisora nacional organiza conciertos obviamente para explotar la fructífera relación juventudmúsica. Los jóvenes brakers de hace unos años viven nuevamente la fiebre, la moda, acompañados, por supuesto, de nuevos seguidores. Pero el apogeo duró lo mismo que el apoyo radial, hasta que aparece Union Society. Esta era una organización en la que se quería explotar el talento joven de la ciudad; en ella roqueros, metaleros, raperos, etc., todos tenían un espacio y organizaban espectáculos.

Posteriormente, una reconocida empresa de medios de comunicación trae una de sus emisoras a Cartagena, especializada en público juvenil. Esta misma empresa radial organizó para todo el país un concurso de todo tipo de música. Muchos raperos reaparecen y participan varios grupos entre los que sobresalen P. S. B., Cosmogónica, Black Power, Killer Konflit, O. P. P. Jurados foráneos eligen a P. S. B., quienes ganaron el derecho a concursar en la gran final que se realizó en Bogotá, compitiendo con numerosos grupos del resto del país, de

\footnotetext{
${ }^{5}$ Esta mezcla desplaza a la terapia, mas no a la música champeta; las voces africanas llegadas vía Europa son desplazadas por Renato, El General y las nacientes voces locales de champeta.
} 
distintos estilos musicales. Una vez más el apoyo radial es efímero. En ese momento unos cuarenta grupos de rap reunían a unos trescientos jóvenes. Es entonces cuando la Secretaría de Desarrollo Social y Humano del gobierno local brindó el apoyo para que se realizara el primer festival de rap en la ciudad entre el doce y el trece de diciembre de 1994, en la plaza de los Coches.

A raíz del festival el movimiento tomó fuerza, había mucho optimismo hacia el futuro. El Maestro apunta: "la consigna era somos bastante, vamos; empieza también el correteo de los políticos a los muchachos del movimiento, que aunque desorganizado tenía unas cabezas visibles". Numerosos grupos de rap, acompañados de fans, amigos de la misma "vuelta", llaman la atención de organizaciones políticas que desean sumarse a la fuerza del movimiento hip-hop de la ciudad. Los jóvenes aceptan la invitación política de una organización universitaria, pero todo se diluyó, sin mayores resultados en pro de los raperos.

El hip-hop afronta para esa época el boom de la champeta criolla; los ya no tan adolescentes breakers pasan del ragga a la champeta criolla, muchos raperos "le entran al 'viaje' de la champeta". De allí surgen figuras como Oscar William, Nando Black, entre otros. A partir del año 1995 se realizan varios concursos en el centro histórico y en barrios periféricos, eventos organizados por los propios jóvenes, algunas veces con apoyo de la radio y de otras empresas. En 1996 una "emisora joven" organiza un concurso del que resultan ganadores 0 . P. P. y Killer Konflit. El premio consistía en "sonarlos en la emisora y hasta ahí". Hasta el surgimiento de organizaciones de raperos como La Heroik, la "vuelta" se vivía en rumbas que organizaban uno o varios grupos, para "vacilarla y obtener algún dinero"; en otras ocasiones las rumbas eran apoyadas por alguna empresa u organización cívica.

Durante el decenio de los noventa los cantantes de hip-hop trabajaban con pistas grabadas, tomadas de los canales de vídeo. Recordemos que para principios de este decenio los servicios de televisión por cable no tenían la misma cobertura que hoy y ni que decir de la televisión vía satélite o el acceso a la red. La otra posibilidad eran las pistas conseguidas con disc-jockeys de reconocidas discotecas, lugares que importaban la música; en otros casos las novedades musicales eran traídas por amigos. Del préstamo y el regrabado, los jóvenes obtenían las pistas, es decir, el andamiaje sonoro donde montaban sus líricas, la letra de las piezas musicales. Poco a poco, el acceso a las redes de información y a las nuevas tecnologías de producción de sonidos, permitieron que los raperos empezaran a producir sus propias bases rítmicas, siguiendo las pautas de creación de los precursores del hip-hop, es decir, sumando elementos locales. 
Hoy la "vuelta" se hace visible más que todo desde organizaciones más o menos estables e informales, donde los jóvenes artistas intentan con sus recursos y disposición temporal hacer sus propios CDs financiados con eventos a los que asisten familiares, amigos y gente cercana al hip-hop, además de intentar constantemente insertarse en los medios.

Casi decenio y medio después de la llegada del break y el rap, los raperos tienen la idea de organizar y unificar lo que ellos llaman el "movimiento hip-hop", de donde surgen al menos dos importantes "bonches" de jóvenes, que utilizan sus recursos tecnológicos, las relaciones personales de sus miembros, las relaciones con otras prácticas culturales que puedan aportar tecnología y más relaciones.

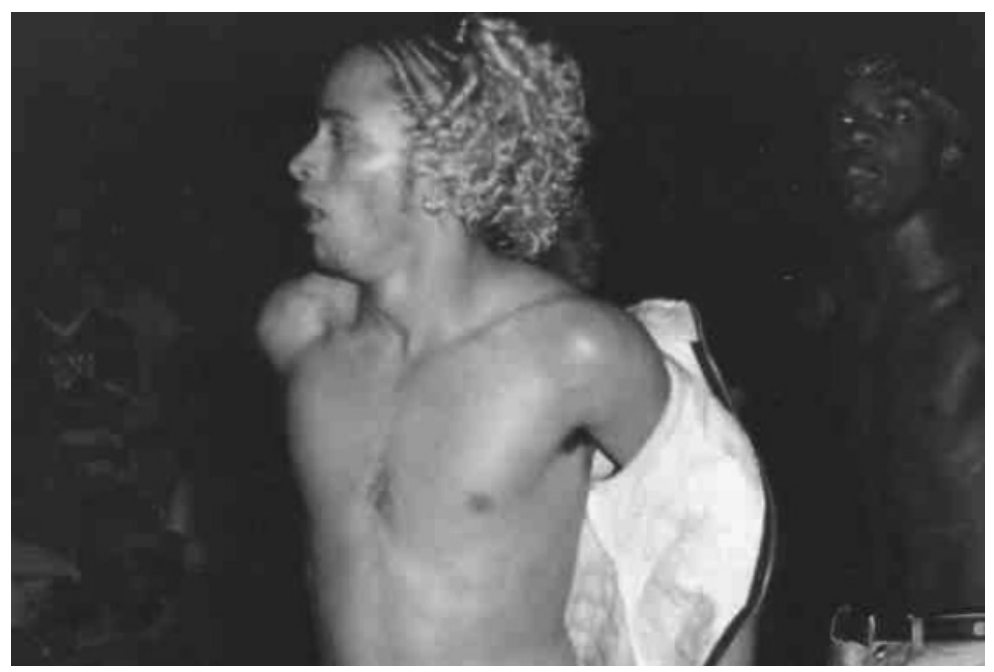

Bailarines en un evento organizado por La Heroika (2002).

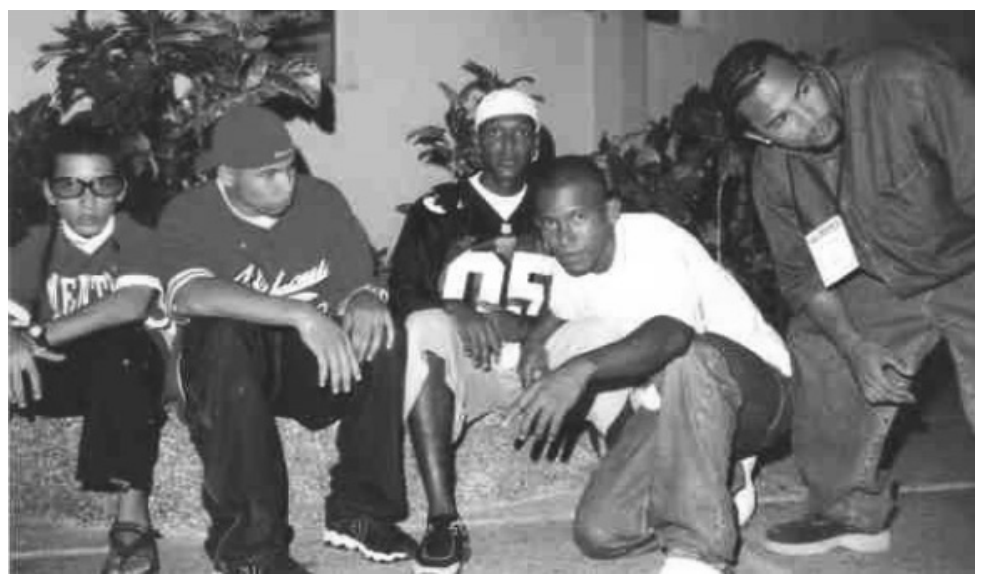

Integrantes de La Heroika Movimiento Hip Hop: Memo, Daver y amigos (2002). 
La Heroik Movimiento Hip-Hop ${ }^{6}$ ha congregado a muchos grupos de jóvenes de distintos sectores de la ciudad. Se dedican a aprender el origen y desarrollo del hip-hop, a colaborar con los jóvenes que se inician, a mantenerse informados y a autofinanciar sus producciones; además de apoyarse y, como organización, crear contactos. Las reuniones y el hecho de darse a conocer como organización les ha posibilitado cierta visibilidad en el ámbito cultural de la ciudad.

El desarrollo del hip-hop en Cartagena ha estado marcado por la relación delos jóvenes con los canales decable, el cine norteamericano, el acceso paulatinamente creciente a tecnologías, y por supuesto, con el desarrollo nacional y local de la radio, la televisión y la entrada de las redes cibernéticas de información, sumando todo esto a una permanente búsqueda de referencialidad.

\section{"Saludando allá al compae Peyo que está allá con las abarcas negras" (Hábito costeño). Entre la calle y la metáfora}

Ocurre que cuando este estilo musical es tomado como base, como escenario, por jóvenes cartageneros para balbucear, gritar, cantar sus preguntas, sueños, burlas, respetos, surge la pregunta sobre qué es lo que posibilita esta identificación. Antes de intentar una respuesta revisemos algunos apartes de las producciones simbólicas de los jóvenes raperos, tomando como referencia las líricas que leímos y escuchamos cantadas por sus creadores. En las líricas del hip-hop el lenguaje está profundamente marcado por el registro popular, es directo, generalmente, aunque también deja lugar a las metáforas:

Arrecostao en la hamaca/ Enfrente al palo e coco/ Tenía una cerveza/ Y mi vecina hedionda a jopo/ El fantasma estaba/ Un tanto intranquilo/ Y ese culo e sol/ Que me tenía bien aburrío/ Eche no joda!/ Qué está pasando/ Veo a una mujer/ Y a unos niños llorando [...].

\footnotetext{
${ }^{6}$ La otra comunidad más o menos definida es la de Los Buenos Muchachos, que tiene su influencia sobre todo en los Calamares y barrios aledaños. Es importante resaltar el interés de estos jóvenes por proveer al movimiento hip-hop de la ciudad en un medio de información. Publicaron una revista, Documento hip-hop, con la que se deseaba tener un espacio de difusión propio. Sabemos por conversaciones con algunos de sus miembros que este "bonche" funciona muy informalmente, no tiene un lugar de reunión estable, ni un horario. Parece que sus actividades grupales son relativamente exitosas, entre ellas se cuenta la publicación de Documento hip-hop, un CD y varias rumbas para amenizar la "vuelta"; sin embargo, las condiciones de reunión señaladas no nos permitieron el acercamiento al grupo como tal, mas sí conversaciones con algunos de sus participantes.
} 
Queremos contrastar esta lírica de Aspecto Raro con una muestra de las creaciones de News Paper, para ejemplificar estos dos tipos de registro:

Despierto entre sueños de guerras y tormentos alucinando odiseas mitológicas. Como un demonio el pasado viene a mí luchando en la vida hasta morir. Enfrentando minotauros que devoran las masas cruzando laberintos de políticas vanas perdido en la guerra que no para con un dulce aroma que devora las entrañas. Las calles cual sirenas me llevan a sus pies atraído por su canto de sonrisas entre llantos me hundo en el infierno acabando con mi vida [...].

News Paper es un grupo que tiene catorce años de existencia, siempre con los mismos integrantes: cuatro jóvenes de Blas de Lezo. Ellos expresan que sus líricas buscan un efecto complejo en la mente del escucha, "una metáfora es una cuestión que al escucharla produce mensajes distintos en la persona, puede que la entienda, pero tiene un montón de significados, como el Apocalipsis", apunta Robert Experto NP. Nótese que el uso de uno u otro registro también entrañan una finalidad. En el primero es contar con un aire coloquial una situación posiblemente violenta. El segundo caso busca deliberadamente la complejidad para dar cuenta de la misma situación.

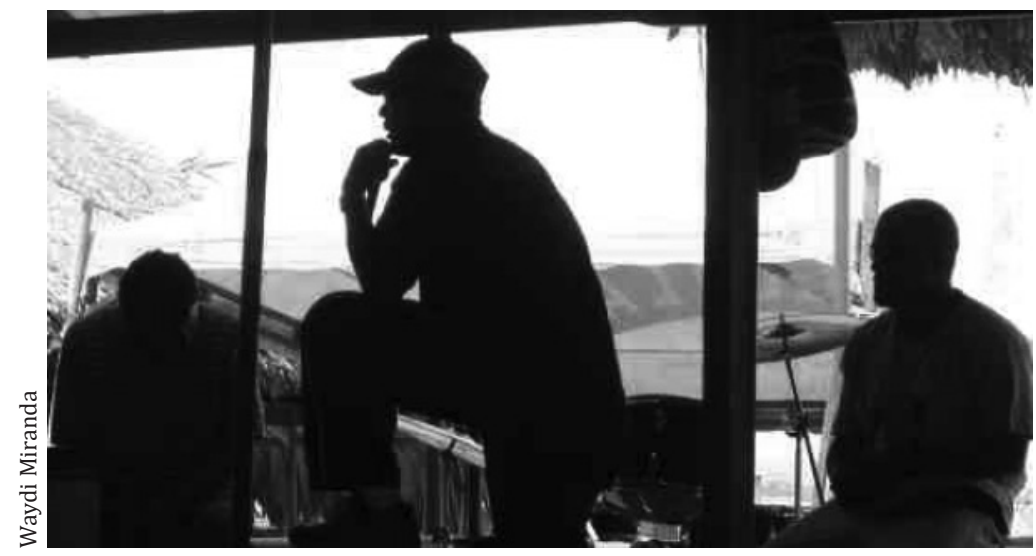

Integrantes del grupo News Paper (2007).

El léxico de las canciones también está influenciado por palabras del inglés, además de voces mezcladas: party, man, men, you, flow, "watcha", "guiales" (girls), "fuck you", "mother fuck", entre otras. En realidad, no existe un léxico extenso que marque una distinción con otras prácticas culturales. Lo anterior ha sido discutido en el seno de la propia comunidad. En La Heroik algunos raperos están convencidos de que un rapero no debe expresarse lo mismo que 
un "champe"; otros sostienen que las palabras no son propiedad de nadie y que los raperos hacen parte de una sociedad, que tienen una lengua que escuchan a diario, que es la del vecino, la de la mamá, no piensan que la de ellos deba ser diferente. Esta discusión brindó el contexto para que Griot realizara una lírica titulada " $\mathrm{Pa}$ ' la que sea":

Sábado en la noche/ Tremendo derroche/ Fantoche azaroso/ El man no era hermoso/ Llega a una fiesta del cual no es invitao/ Pero se ha sentao/ Y una fría se ha tomao/ Me impresiona que a ese man/ Nadie lo haya parao/ Revienta champeta/ Se espeluca/ Y va pa' esa/ A la quinceañera escoge como presa/ Me impresiona que ella no se ha negao/ El la ha apretao y la ha arrecostao/Dios mío qué es lo que pasa/ Yo me he preguntao $\mathrm{Pa}^{\prime}$ no quedarme con la duda pregunte por el sujeto/ Me dijo un valecita pana mijo quédese quieto/ [...]/ Domingo en la mañana/ Yo me he leventao/ Me quede donde mi vale/ Por que el barrio era pesao/ Salimos a una esquina azarando parche/ Buscando una lea que conmigo se marche/ De repente dos tombos/Llevan a un man esposao/ Ya ustedes saben como e'eso/ Una manduquera le han dao [...].

El Maestro, cantautor del grupo Griot, quiso mostrar cómo es posible rapear con cualquier léxico, aunque a un oyente ajeno a la discusión puede parecerle que se intenta mostrar violencia o la vida de bajo mundo.

Otro aspecto a analizar en las líricas es el de las temáticas que se presentan con mayor insistencia. La religiosidad, las disputas y las jerarquías al interior de la comunidad, la condición de rapero y el señalamiento por parte de la sociedad son temas muy recurrentes. Memo Reflexión es un cantante de rap que se caracteriza por utilizar el tema de la fe, Dios, los buenos principios, en casi todas sus líricas, incluso cuando la lírica es para cuestionar el trabajo o la actividad de otro rapero: "Hoy señor te pedimos perdón/ Porque somos de la carne/ Y por ella pecamos/ [...]/ Con misericordia y verdad se corrige el pecado [...]“. En relación con el segundo aspecto veamos el dúo que hace con Deiver Coleto: "La olla podrida se ha destapado/ Gente hipócrita a montón he encontrado/ Te saluda como Judas/ Y te dan la pedrada/ Cuando das la espalda hablan mal de ti/ Es un trauma de inferioridad lengua viperina/ diablo rojo pa'tu lengua". Memo: "Dios manda que sólo hagas lo bueno/ aparta la maldad de tus instintos [...]". La referencia a Dios es una constante en muchos grupos de hip-hop. Un rapero de la calle afirma: "a la gente le gusta colaborar si le hablan de Dios". Hábito Costeño es otro grupo que se inscribe en esta línea temática: 
Estando en el hueco solo yo perdido/ El padre celestial me ha sacado del abismo/ Mandando lírica a través de sus discípulos/ Bien encaminado justo sabio bueno/ [...]/ siento en el alma la Biblia bien adentro/ que corre por mis venas./ Ojos espirituales hay en tu alma/ Quítate la venda y escucha esta palabra/ Escucha la doctrina de los sabios que le atacan/ ¡Ay hombre!/ Rompe las cadenas del mal/ Si quieres que las cosas cambien/ Comienza por tí/ No te dejes llevar/ Abre esos ojos espirituales/ Que están en lo más profundo de tu alma.

En lo que respecta a la jerarquía y la calidad del grupo, la mayoría de las líricas están dedicadas a resaltar al grupo, a "tirarle", es decir, a retar a los otros y también a incentivar a los nuevos adeptos cuando se trata de cuestionar a los otros grupos. Aunque pensamos que también esto se toma como excusa para desplegar la propia fuerza ante un enemigo que encarna elementos externos a "la vuelta":

Esta vida de un rapero señalado con un dedo/ Por la espalda hablan varios que no somos vendedores/ Por la espalda hablan varios que no somos vendedores/ Por la espalda hablan varios que no somos vendedores/ Hiphoper vienen, raperos van/ Pasa la fiebre los propios aquí están. (El Orgullo de la Vieja).

De otro lado, la ciudad penalizada es pensada en el hip-hop desde los espacios marginados. Este eje temático se presenta no sólo en las líricas del corpus, sino también en toda la producción simbólica de la comunidad. Aunque se da también una representación de la ciudad playa, sol, brisa y mar, es decir, la ciudad imaginada para el turismo, también se nota el orgullo por el swing del cartagenero, su destreza y sensualidad en el baile. Veamos dos ejemplos,

En el patio de mi casa/ Al fondo mi abuelo/ El individuo con el tabaco/ Y el licor en el cerebro/ Salgo a la calle/ [...]/ De repente un visaje/ Un sujeto endrogao/ Maltratando a su madre/ [...]/ Caminando por la calle siempre veo lo mismo/ Pura destrucción y la gente con egoísmo. (Tribu Nativa).

Sexy movimiento/ Ya lo puedes tú sentir/ Caliente como el sol que quema/El día en la playa/De mi Cartagena/Y continuando con mi relajo/ Oye mi hermano es producto/ Cien por ciento colombiano/ [...] / Formando con el espeluque/ Con el swing de Cartagena/ Orgulloso estoy de mi corralito é piedra/ De mi Colombia/ De esta gran hermosa tierra. (La Fusión Latina). 
La temática del rapper como artista y como joven, viviendo su condición ante la mirada estigmatizadora y lo inevitable, el trabajo y el imperativo, a veces anhelo de producir económicamente, de organizarse, son líneas temáticas de las más fuertes. En las líricas se observa un deseo de legitimación y una lucha por sostenerse en su cultura, de la mano de un deseo por surgir:

De la calle la music para tus odios/ Gente en la calle engañada conmigo. Raperos aparentes me dicen demente/ [...]/ Por el hip-hop me hago crucificar/Yo tengo un don y nací verdadero/ [...]/ Que Lennín está loco que perdió la razón/ Loco le decían a Fidel Castro/ Loco le decían a Napoleón/ Loco le dicen al que te canta/ Loco bien loco estoy yo. (Lenín Torcido).

Además de estas temáticas se pueden observar en el hip-hop unos índices, unos signos que no constituyen temáticas generalizadas, pero que están latentes. Estos índices son ricos porque las líricas son bastantes complejas. El léxico es trabajado en busca de un efecto de sonido, y sobre éste, ya en la cotidianidad, se quiere fundamentar una "filosofía cultural de raíces". Ello es una constante en Hábito Costeño. Miremos otra de sus líricas: "Dialécticas diferentes/ Poseo destreza y arte/ Mis sentidos se agudizan/ Descargando melodías/ Para mantener mi órbita/ [...]/ Este efecto de metafísica/ energía de origen étnico/ [...]/ tirando mente/ para que esto sea vacano/ Mantengo mi órbita/ permaneciendo/ Mantengo mi órbita así lo hacemos/ Creando con efecto un hip-hop cartagenero". Otro índice es el de la lírica que busca crear conciencia, aconsejar sobre los peligros que acechan a los jóvenes. Este es el estilo de Descarga:

\begin{abstract}
Decisiones transforman horas en segundos/ En este mundo buscando cierta meta cerca/ La más directa/ Elegir condiciones la intelectual/ Es nuestra vida buena plena/ La más segura solo tiene una salida pura/ [...]/ Luego me aparto de esto/ Y voy directo para cumplir con lo inquieto/ Chicos a diario van a una disco/ Conocen a una chica/ Que nota afino/ Luego ocurre lo inesperado lo buscado/ Beso en tu boca por todo lado/ El cuerpo estremece mece/ Esperamos ahora nueve meses/ Que chamo lindo/ Fiesta en tu casa/ Decisiones tomadas sin pensar en nada [...].
\end{abstract}

Los jóvenes sintetizan la gaita y el bajo sin ningún conflicto, al estar cruzados ellos mismos por una tradición musical personal, es decir, lo aceptado de lo que se recepciona desde lo dado por los discursos institucionales sobre "nuestra música", y también por las mediaciones musicales llegadas desde los medios y la industria del disco. 


\section{Músicas, identidades y desconfiguraciones}

Veamos este testimonio respecto a las músicas locales y músicas foráneas como el merengue.

Robert:

Hay unas champeticas que son buenas, pero yo sigo pensando que la champeta es una degradación de la música africana, me gusta la salsa; la cumbia, porque es algo que es nuestro, el merengue no es que me guste sino que no me afecta el oído [...] el vallenato no existe en mi configuración mental, mi cerebro está totalmente desconfigurado para esa música.

En el mismo sentido, el Hombre Verde, integrante de La Fusión Latina: "El que es pa la yuca con suero es pa'la yuca con suero y el que es pa'l hip-hop es pa'l hip-hop." Los creadores del hip-hop casi nunca son músicos de formación académica, por ello el acceso a ciertas tecnologías de sonido es un factor determinante. Primero el sampling, y luego la mezcla computarizada, han brindado estrategias para superar esta falencia. Wilson, integrante de Así de Sencillo, nos ilustra:

Antes el que tenía una pista era el rey, antes se cantaba con los movimientos de la boca y las manos, aunque eso no se llama rap; luego se 'sampleaban' las pistas, se cogía el disco se le sacaban las voces y se usaba sólo la pista [. . .] ahora se hace por computadora, dicen que queda mejor, yo pienso que sí y cada quien hace su propia pista.

Si consideramos que el hip-hop no es producto de conservatorios musicales, ni para el interés de celosos musicólogos, sino que es nacido en los parques, las calles, centros comerciales, pensado para el cuerpo, esta carencia que señalábamos no es tal. Lo que los creadores del hip-hop buscan es un sonido para la euforia transitoria del "party"; su finalidad inmediata es el "feeling", la conexión directa con el sonido que deja paso a la diversión.

\section{La misma "vuelta" vista desde los supuestos teóricos de la investigación}

Retomemos desde aquí la pregunta acerca de qué es lo que posibilita la conexión de estos sujetos con el hip-hop. Efectivamente los medios y el mercado sí han sido protagonistas en dicha conexión: las tardes de video en casa del amigo que tenía televisión con antena parabólica, por ejemplo, marcaron la orientación de los jóvenes 
hacia el rap, "vacilarla" con un estilo de ropa puede llevar a conocer a personas con gustos afines, y podríamos seguir con una extensa lista de evidencias que no carecen de importancia, pero nos quedaríamos en el nivel superficial del asunto. Es necesario el análisis de los efectos de estos elementos en la producción simbólica de los sujetos culturales.

El efecto de las mediaciones disparadas por la globalización llega más allá, al ámbito de las representaciones simbólicas que devienen en pluralidad y múltiples conexiones que hacen imposible la realidad en singular, y por ende, la representación de ella y los modos de ver y mostrarse de los sujetos. Sugerimos que el hip-hop es una propuesta muy consecuente de estos jóvenes para interpelar su contexto cultural, sin olvidar que este último es ya de construcción mediática.

Demasiados sentidos entrelazados sólo les deja a los jóvenes la posibilidad de indagarse en lo simbólico. Así las cosas, si un sonido nuevo les brinda una pared para expresar esas mediaciones simbólicas que los forman, la construcción de un sentido propio es la respuesta a la necesidad de autorrepresentación. El rap se presenta como un ritmo mercenario, a sueldo de las necesidades expresivas de los automarginados del mundo, inevitable del que huye gritándole sus defectos y ostentado poder. Este estilo musical no es la música foránea que viene a enajenar, puesto que en el ámbito simbólico donde se construyen las referencialides de los sujetos esta postura se agota arrasando también las categorías de lo propio y lo ajeno; si aún queda algún lugar para las esencias es si consideramos que en este momento del desarrollo de la cultura occidental los sujetos culturales son esencialmente puntos de cruce de mediaciones.

Lo que estamos diciendo es que para el caso que nos ocupa las matrices tradicionales no tienen un estatus dominante. La escuela o la religión, por ejemplo, son sólo una fuente más, otra coordenada que cruza y que es constantemente resemantizada por las mediaciones tecnológicas, de mercado etc. No preferir la cumbia al merengue dominicano no implica el reconocimiento de una tradición musical local, si no cómo se explica la desconfiguración del oído para el vallenato.

Además es posible considerar que el origen ya problemático en cuanto a lo social y también complejo en lo que respecta a la parte sonora del hip-hop, le da todas las características para hacer eco en unos sujetos cuyos problemas de referencialidad devienen de los complicados cruces que los forman como individuos y como comunidad. Luego, más que al sometimiento y amenaza de lo tradicional -lo cual 
homologaremos aquí con el mundo adulto (sin olvidar lo difuso, contradictorio e irreductible de esta categoría) pensándolo como el lugar de lo dado, lo establecido, regulado por unas instituciones y que posee unos discursos más o menos definidos- asistimos a la negociación que el mercado y las industrias culturales hacen de la tradición ante unas matrices tradicionales que esgrimen una postura que va desde la complicidad y la admiración hasta el cuestionamiento, pero en ningún caso la confrontación directa.

La relación entre los jóvenes y el rap obedece a una satisfacción simbólica. El hip-hop se convierte en un esquema de representación válido precisamente por su conexión mediada con la realidad, porque los pone a tono con lo nuevo, lo actual, dejándole posibilidades de conexiones telúricas con elementos de las matrices culturales tradicionales. Está también su origen doble de sonido de la gran urbe, pero también de pobreza y resistencia, sin olvidar las ramas afrocaribeñas con profundas raíces africanas, representadas en el ritmo, la energía corporal y la figura del griot. Este sonido brinda a los jóvenes la posibilidad de crearse a sí mismos desde lo simbólico y a la vez divulgar el propio conocimiento del mundo. Es este conocimiento lo que unifica sentidos en las líricas del hip-hop.

Esta búsqueda de sentido y conciencia de un saber propio sobre el mundo puede rastrearse también en los rituales de puesta en escena, y no hablamos sólo de elementos como el vestuario, el cuerpo, sino también de los discursos que circulan alrededor de las líricas, los puntos de vista en las conversaciones cotidianas, sin el micrófono. Allí se puede observar esta fuerte lucha por la referencialidad.

Desde la música se ponen en circulación unos argumentos, marcas identitarias, negaciones, jerarquizaciones, negociaciones con los cruces que los sujetos simbólicos sufren desde las matrices tradicionales y desde las mediaciones. Por ejemplo, la gaita como metonimia de la tradición en varios grupos, y muchos otros elementos más, son entonces inscritos como otro recurso, o simplemente se les "mama gallo" para pasarla bien o demostrar algo. Vista desde dentro, es decir, desde la observación y el análisis de sus distintas discursividades, esta práctica cultural se presenta como una cultura diaria, como un modo de pensamiento y de vida en conflicto, interrogación y conjugación con la modernidad, la mediada cotidianidad y el afán de construir un estatus cultural válido.

Una práctica cultural construida alrededor de una música y unos rituales de consumo conforma para los jóvenes "nuestra manera" de ver, de ser, de entender, de explicar, de "abrirse" o agruparse. 
Una suerte de artefacto simbólico con el que los miembros de la comunidad se sienten ser un "yo" o un "nosotros", distinto de los "otros", que a su vez tendrán sus propios contextos explicativos.

Este artefacto simbólico es producto de varios procesos históricos, económicos y sociales que se han ido configurando con el transcurrir del tiempo y la cultura, puntos de referencia que se mantienen en la mutación, en la no esencialidad de la permanencia, y por supuesto, en la imposibilidad de la identidad en singular, pura, inmutable y perfectamente reconocible. El rap se presenta entonces como un artefacto simbólico, construido desde la problemática de unos sujetos culturales visualizados como consumidores y a la vez objetos de consumo, insertos en unas coordenadas históricas, culturales, económicas y políticas complejas.

El rap cartagenero no es una música del repertorio musical institucionalizado como tradicional y no sufre el furor coleccionador de los musicólogos, a pesar de la importancia que tiene en el ámbito juvenil, y tampoco ha sido protagonista de la poca investigación cultural que se realiza en la ciudad, en contraste con lo que ocurre en otras ciuda-des del país. Se han hecho algunas exploraciones desde el periodismo, pero el interés no estaba en la riqueza creativa de los jóvenes o el poder simbólico de las líricas, sino en la violencia de las pandillas, que durante los últimos decenios del pasado siglo hicieron visibles a los jóvenes en la ciudad.

Queremos cerrar este acercamiento al hip-hop cartagenero señalando algunos aspectos que quedan por estudiar:

a. Las posibilidades pedagógicas que podría tener esta práctica cultural en el ámbito estudiantil, si se analiza qué posibilita que en determinados contextos de la vida escolar se permita la puesta en escena de los jóvenes raperos, a la par de la presentación de las músicas tradicionales, y que al mismo tiempo se penalicen elementos de la misma puesta en escena por fuera de estos contextos, sin tener en cuenta que el rapero, a diferencia de la cumbiambera, siempre está en escena.

b. La constante creación, transformación, desintegración de grupos y las motivaciones que llevan a los raperos a trabajar en buses.

c. Estudiar a profundidad los corpus sonoros que cruzan esta música. 
d. El desarrollo de las comunidades que se están formando, su desarrollo y propósitos, los intentos de inserción que buscan dentro de los medios radiales, televisivos e impresos.

e. Las pedagogías informales con las que los jóvenes aprenden y se enseñan las técnicas de canto, grabación y los rituales de puesta en escena.

\section{Bibliografía}

García Canclini, Nestor. (1990). Culturas híbridas: estrategias para entrar y salir de la modernidad. México D.F.: Grijalbo.

García Usta, Jorge. (Dic. 5 de 1995). "Pandillas y muerte en el Suroriente (II): Hambre, breakdance y pistolas", en El Periódico de Cartagena, pp. 4B-4C.

Martín-Barbero,Jesús.(1998). De los medios a las mediaciones: comunicación, cultura y hegemonía. Santa Fe de Bogotá: Convenio Andrés Bello.

Marín, Marta y Muñoz, Germán. (2002). Secretos de mutantes: música y creación en las culturas juveniles. Bogotá: Siglo del Hombre Editores.

Cubides, Humberto, Laverde, Ma. Cristina \& Valderrama, Carlos. (Eds.). (1998). Viviendo a toda: jóvenes, territorios culturales y nuevas sensibilidades. Bogotá: Siglo del Hombre Editores

Martín Serrano, Manuel. (1997). "La mediación de los medios", en Martín-Barbero, Jesús \& Silva, Armando. (comps.). Proyectar la comunicación. Bogotá: Tercer Mundo Editores.

Perea, Ángel. (1996). "El sonido y la furia, la historia del rap", en Revista Papeles Juveniles, No. 4. Bogotá: Ministerio de Educación.

Reguillo Cruz, Rossana. (2000). Emergencia de culturas juveniles: estrategias del desencanto. Bogotá: Editorial Norma.

Serrano, Amaya, José Fernando. (1998). "La investigación sobre jóvenes: estudios (y desde) las culturas", en Cultura medios y sociedad. Bogotá: CES Universidad Nacional.

Ochoa, Ana María \& Cragnolini, Alejandra. (coord.) (2002). Músicas en transición (Cuadernos de Nación). Bogotá: Ministerio de Cultura y El Ancora Editores.

Wade, Peter. (2002). "Construcciones de lo negro y del África en Colombia: política y cultura en la música costeña y el rap", en Mosquera, Claudia, Pardo, Mauricio y Hoffmann, Odile. (Eds.). Afrodescendientes en las Américas. Bogotá: Siglo del Hombre Editores. 